\title{
VALIDASI APPROACHES TO LEARNING AND STUDYING INVENTORY DI FAKULTAS KEDOKTERAN UNIVERSITAS GADJAH MADA YOGYAKARTA
}

Michael A. Leman*, Rossi Sanusi**, Yayi Suryo Prabandari**

* Mahasiswa S2 Ilmu Pendidikan Kedokteran, Fakultas Kedokteran UGM

** Dosen Bagian Pendidikan Kedokteran, Fakultas Kedokteran UGM

\begin{abstract}
Background: Short version instruments are being developed to meet the needs of social sciences researchers who simulataneously use a number of instruments. The Approaches to Learning and Studying Inventory (ALSI) is a short version instrument to measure learning approaches used by students. This analysis is part of a study that is published in different medical education periodicals. The objective of this assessment was to validate the ALSI in a population of second year medical students of the Gadjah Mada University Faculty of Medicine (GMU FM), Yogyakarta.

Method: 225 second year students in the regular program at the GMU FM were invited to complete the ALSI questionnaire. To suport construct validities of ALSI, an item' validity, Crönbach alpha, factor analysis, convergent validity, and discriminant validity were measured.

Results: A total of 160 students participated in this study (71,11\% response rate). The data collected did not support the construct validities of ALSI.

Conclusion: ALSI requires improvement, in particular the items of the surface approach subscale. Instead of the initial five subscales, it is probably more appropriate if the instrument is divided in only three subscales - surface approach, effort management-organized studying, and deep approach-monitoring studying.
\end{abstract}

KEYWORDS: construct validity, factor analysis, ALSI, learning approaches, medical students

\section{ABSTRAK}

Latar belakang: Instrumen versi singkat banyak dikembangkan untuk memenuhi kebutuhan peneliti dalam penelitian ilmu sosial yang menggunakan banyak instrumen. Approaches to Learning and Studying Inventory (ALSI) merupakan salah satu instrumen versi singkat yang digunakan untuk mengukur pendekatan belajar mahasiswa. Penelitian ini merupakan satu bagian dari penelitian yang dilaporkan di jurnal pendidikan kedokteran yang lain. Tujuan penelitian ini adalah untuk melakukan validasi ALSI versi singkat pada mahasiswa tahun kedua di Fakultas Kedokteran Universitas Gadjah Mada (FK UGM) Yogyakarta.

Metode: Sebanyak 225 mahasiswa tahun kedua program reguler FK UGM diundang untuk mengisi ALSI. Validitas konstruk dinilai dengan uji validitas item, Crönbach alpha, analisis faktor, validitas konvergen, dan validitas diskriminan.

Hasil: Sebanyak 160 mahasiswa tahun kedua FK UGM berpartisipasi dalam penelitian ini (response rate 71,11\%). Data menunjukkan bahwa ALSI memiliki validitas konstruk yang rendah.

Kesimpulan: ALSI memerlukan perbaikan, terutama item-item dalam sub skala surface approach. ALSI lebih tepat jika hanya terbagi dalam tiga sub skala, yaitu surface approach, effort management-organised studying, dan deep approach-monitoring studying.

KATA KUNCI: validitas konstruk, analisis faktor, ALSI, pendekatan belajar, mahasiswa kedokteran

Korespondensi: herman.untad@gmail.com 


\section{PENDAHULUAN}

Mahasiswa kedokteran sadar akan tanggung jawab mereka sebagai praktisi kesehatan di masa mendatang, sehingga mendorong mereka untuk menggunakan pendekatan belajar mendalam dalam proses belajar. ${ }^{1}$ Mahasiswa yang menggunakan pendekatan belajar mendalam terbukti memiliki nilai ujian yang lebih tinggi dibandingkan dengan mahasiswa yang menggunakan pendekatan belajar dangkal. ${ }^{2}$ Lingkungan belajar merupakan salah satu faktor yang mempengaruhi mahasiswa dalam memilih pendekatan belajar tertentu. ${ }^{3,4,5}$

Beberapa instrumen telah dikembangkan untuk mengukur pendekatan belajar mahasiswa, di antaranya: Approach to Studying Inventory (ASI ${ }^{6}$; Study Processes Questionaires (SPQ) ${ }^{7}$; Revised Approaches to Studying Inventory (RASI) $^{8}$; Approaches and Study Skill Inventory for Students $(\text { ASSIST })^{9}$; dan Approaches to Learning and Studying Inventory (ALSI). ${ }^{10}$ ALSI merupakan sebuah instrumen yang dikembangkan oleh Entwistle et al. ${ }^{10}$ dalam rangka proyek penelitian mengenai karateristik lingkungan belajar yang mempengaruhi pendekatan belajar mahasiswa. ALSI yang pertama kali dikembangkan berisi 36 item pernyataan dan berasal dari ASI dan RASI. Dalam perkembangan selanjutnya dikembangkan ALSI versi singkat (berisi 18 item).

Peneliti perlu memastikan bahwa instrumen yang digunakan memiliki validitas dan reliabilitas yang baik, karena hal tersebut sangat berpengaruh pada kesimpulan yang diambil berdasarkan informasi yang diperoleh dari instrumen tersebut. ${ }^{11}$ Penelitian ini merupakan satu bagian dari penelitian yang dilaporkan di jurnal pendidikan kedokteran yang lain. Tujuan penelitian adalah melakukan validasi ALSI versi singkat pada mahasiswa tahun kedua di Fakultas Kedokteran Universitas Gadjah Mada (FK UGM) Yogyakarta.

\section{METODE}

ALSI-18 item dikelompokkan dalam lima sub skala, yaitu: deep approach (DA) (6 item); surface approach (SA) (4 item); monitoring studying (MS) (4 item); organized studying (OS) (2 item); dan effort management (EM) (2 item). Setiap item dinilai menggunakan skala Likert 5 poin $(1=$ sangat tidak setuju, 2 = tidak setuju, 3 = ragu-ragu, $4=$ setuju, 5 = sangat setuju). Item dalam sub skala DA dan MS dijumlahkan untuk kategori pendekatan belajar mendalam, sedangkan item dalam sub skala OS dan
EM dijumlahkan untuk kategori pendekatan belajar strategik. Nilai rerata pada kategori yang tertinggi merupakan pendekatan belajar yang digunakan oleh mahasiswa.

ALSI sebelumnya telah diterjemahkan ke dalam bahasa Indonesia pada penelitian Waty. ${ }^{11}$ ALSI terjemahan bahasa Indonesia kemudian diuji keterbacaan sebanyak dua kali. Uji keterbacaan pertama pada lima mahasiswa FK UGM yang dipilih secara convenience sampling (mahasiswa FK UGM yang dikenal oleh peneliti). Instrumen diperbaiki berdasarkan masukan dari uji keterbacaan pertama dan diujikan kembali pada tiga orang mahasiswa FK UGM lain yang kebetulan dijumpai peneliti di lingkungan FK UGM. Semua mahasiswa dalam uji keterbacaan ini bukan merupakan mahasiswa tahun kedua FK UGM. Pada uji keterbacaan yang kedua, tiga mahasiswa tersebut menyatakan bahwa semua item dalam ALSI sudah dapat dipahami dengan baik. ALSI hasil uji keterbacaan diterjemahkan kembali ke dalam bahasa Inggris oleh lulusan Fakultas Sastra Inggris dari Universitas Sanata Dharma Yogyakarta. Hasil penerjemahan kembali dan ALSI yang asli dievaluasi kembali untuk melihat kesesuaian makna antara hasil perbaikan yang telah diterjemahkan dalam bahasa Inggris dan instrumen asli.

Sebanyak 225 orang, yang merupakan populasi mahasiswa tahun kedua di program reguler FK UGM dan sedang mengikuti blok 2.2 (Safe Motherhood and Neonates), diundang untuk mengisi ALSI pada bulan Oktober 2013. Penelitian ini menggunakan rancangan potong-melintang. Kriteria inklusi dalam penelitian ini adalah mahasiswa yang tercatat sebagai mahasiswa inti tahun 2012, sedangkan kriteria eksklusi adalah mahasiswa tahun kedua Program Internasional FK UGM dan bukan mahasiswa yang mengalami turun semester atau mengikuti double block. Mahasiswa program Internasional tidak diikutkan dalam penelitian karena memiliki bahasa yang berbeda dalam komunikasi dan waktu pelaksanaan blok tidak sama dengan program reguler.

Mahasiswa tahun kedua FK UGM dibagi dalam dua kelompok oleh Bagian Akademik FK UGM, sehingga pengumpulan data dilakukan pada kedua kelompok di waktu yang berbeda. Pada saat pengumpulan data peneliti ditemani oleh satu asisten peneliti dan berada di dalam ruangan untuk menjawab pertanyaan 
seandainya terdapat hal-hal yang tidak dipahami oleh mahasiswa. Informasi penelitian diberikan terlebih dahulu sebelum kuesioner diisi oleh mahasiswa. Waktu yang diberikan untuk mengisi kuesioner adalah sepuluh menit dan semua mahasiswa mengisi kuesioner secara lengkap sesuai dengan waktu yang diberikan. Dalam lembaran kuesioner yang diisi, peneliti meminta mahasiswa untuk menuliskan identitas mereka (nama, jenis kelamin, dan alamat e-mail).

Statistik deskriptif digunakan untuk menggambarkan pendekatan belajar yang digunakan oleh mahasiswa. Analisis data dalam penelitian ini menggunakan perangkat lunak statistik. Dalam penelitian ini, dilakukan uji validitas konstruk pada instrumen ALSI dengan menggunakan lima cara. Pertama, uji validitas setiap item dengan menggunakan uji korelasi Pearson Product Moment yang dilakukan dengan cara mengkorelasikan skor masing-masing item dengan skor total. Suatu item dinyatakan valid jika $r$ hitung $>\mathrm{r}$ tabel. ${ }^{12}$ Nilai $\mathrm{r}$ tabel diperoleh dari nilai degrees of freedom $(\mathrm{df})=\mathrm{n}-2(\mathrm{n}=$ besar sampel), sehingga diperoleh nilai $\mathrm{r}$ tabel pada nilai df (158) dengan tingkat kemaknaan 0.05 adalah 0.1522 . Kedua, dilakukan uji reliabilitas instrumen dengan menghitung nilai internal consistency (Crönbach alpha). Suatu instrumen dikatakan memiliki nilai reliabilitas yang tinggi jika Crönbach alpha $\geq 0.70 .{ }^{13}$

Ketiga, dilakukan analisis faktor, yaitu confimatory factor analysis (CFA) dengan membandingkan susunan item masing-masing sub skala sama sebelum dan sesudah dianalisis. Hal-hal yang diperhatikan sebagai berikut: 1) nilai Keiser-Meyers-Oklin (KMO) $>0.6$ dan nilai Barlett test of Sphericity menunjukkan tingkat kemaknaan ( $\mathrm{p}<0.05$ ), sehingga data dapat dianalisis lebih lanjut; 2) nilai eigenvalues $\geq 1$ menunjukkan jumlah komponen yang terbentuk dari sejumlah item yang dianalisis; dan, 3) nilai korelasi yang terbesar dari item dalam suatu komponen digunakan untuk menentukan pengelompokan item dalam suatu komponen tertentu.

Keempat, dilakukan uji validitas diskriminasi untuk melihat dua atau lebih item dalam sub skala yang berbeda memang berbeda, sehingga ditetapkan hipotesis bahwa korelasi antara setiap item dalam sub skala yang berbeda memiliki hubungan yang lemah $(r<0.6)$. Kelima, dilakukan uji validitas konvergen untuk melihat "apakah sub skala - sub skala yang terdapat dalam instrumen mengukur satu konstruk” dan memiliki nilai korelasi yang kuat $(r>0.6)$ dan semua sub skala hanya dikelompokkan dalam satu faktor pada saat dilakukan analisis faktor.

\section{HASIL DAN PEMBAHASAN}

\section{Deskripsi pendekatan belajar mahasiswa}

Sebanyak 160 (71,11\%) mahasiswa tahun kedua FK UGM mengisi kuesioner dengan lengkap. Dari 160 orang tersebut, terdapat 93 orang perempuan $(58,12 \%)$ dan 67 orang laki-laki (41,87\%). Berdasarkan hasil analisis data, terdapat 103 orang menggunakan strategi mendalam (63,75\%), 52 orang menggunakan pendekatan belajar strategik (32,5\%), dan enam orang menggunakan pendekatan belajar dangkal (3,75\%).

Response rate dalam penelitian ini cukup rendah. Kesulitan mencari waktu kosong mahasiswa untuk pengumpulan data yang disebabkan karena jadwal perkuliahan mahasiswa di blok 2.2 sangat padat. Peneliti telah berusaha melakukan koordinasi dengan koordinator mahasiswa tahun kedua sebelum pelaksanaan pengumpulan data. Namun, pembagian mahasiswa dalam kelompok kecil mengikuti model pembelajaran problem-based learning menyebabkan masing-masing kelompok memiliki jadwal yang berbeda, sehingga sulit untuk mengumpulkan mahasiswa dalam satu waktu. $\mathrm{Hal}$ ini berdampak pada response rate yang rendah dalam penelitian ini.

Pengumpulan data yang dilakukan dalam penelitian ini cukup reliabel dan pada saat memberikan informasi awal, peneliti meminta mahasiswa untuk mengisi alamat $e^{-}$ mail dengan tujuan untuk mengirimkan hasil interpretasi kuesioner yang telah mereka isi. Dari 160 orang mahasiswa dalam penelitian ini hanya 11 orang yang tidak menuliskan alamat e-mail. Hal ini membuktikan bahwa sebagian besar mahasiswa tertarik pada informasi hasil pengisian kuesioner yang mungkin bermanfaat untuk bahan evaluasi dan pengembangan diri mereka (bahan refleksi tentang strategi belajar yang selama ini mereka gunakan).

\section{Validasi ALSI}

Empat item pernyataan (item no. 1, 5, 13, dan 17) dalam sub skala SA memiliki nilai $r<r$ tabel $(r>0.1522)$, sehingga item tersebut tidak valid (lihat Tabel 1). 
Tabel 1. Corrected item-total correlation pada tiap item dalam ALSI

\begin{tabular}{|c|c|c|c|c|c|c|c|c|c|}
\hline SA & $\begin{array}{l}\text { Comrected } \\
\text { Item-Total } \\
\text { Comelation }\end{array}$ & MS & $\begin{array}{l}\text { Corrected } \\
\text { Item-Total } \\
\text { Comrelation }\end{array}$ & DA & $\begin{array}{l}\text { Comrected } \\
\text { Item-Total } \\
\text { Correlation }\end{array}$ & EM & $\begin{array}{l}\text { Corrected } \\
\text { Item-Total } \\
\text { Correlation }\end{array}$ & OS & $\begin{array}{l}\text { Comrected } \\
\text { Item-Total } \\
\text { Comrelation }\end{array}$ \\
\hline 1 & .094 & 2 & .316 & 3 & .381 & 4 & .520 & 7 & .317 \\
\hline 5 & -.166 & 10 & .288 & 6 & .371 & 15 & 189 & 11 & .425 \\
\hline 13 &. .172 & 14 & .382 & 8 & .327 & & & & \\
\hline \multirow[t]{3}{*}{17} & -189 & 18 & .295 & 9 & .279 & & & & \\
\hline & & & & 12 & .296 & & & & \\
\hline & & & & 16 & .214 & & & & \\
\hline
\end{tabular}

Dicetak tebal $=\mathrm{r}$ hitung $>\mathrm{r}$ tabel, menandakan item valid.

$\mathrm{SA}=$ surface approach; $\mathrm{DA}=$ deep approach; $\mathrm{MS}=$ monitoring studying; $\mathrm{OS}=$ organised studying; EM = effort management

Dari lima hipotesis alat ukur yang ditetapkan dalam penelitian ini untuk menguji validitas konstruk tidak ada satu dari hipotesis tersebut yang berhasil dipenuhi oleh ALSI secara lengkap. Dalam penelitian ini ditemukan empat item dalam ALSI yang tidak valid dan hasil ini berbeda dengan yang ditemukan oleh Waty. ${ }^{11}$ Nilai reliabilitas pada sub skala SA juga cukup rendah (Crönbach alpha $=0.64$ ) dalam penelitian Mattick et al. ${ }^{14}$ Berdasarkan hasil penelitian ini mungkin item pernyataan dalam sub skala SA perlu diperbaiki karena kurang tepat untuk mengukur konstruk pendekatan belajar dangkal.

Nilai Crönbach alpha ALSI-18 item adalah 0.522. Berdasarkan analisis faktor ALSI diperoleh nilai KMO sebesar 0.782 dan Barlett test of Sphericity menunjukkan tingkat kemaknaan $(p=0.000)$, sehingga data dapat dianalisis lebih lanjut. Berdasarkan hasil uji total varians explained terlihat kelima faktor yang terbentuk dapat menjelaskan 54,076\% dari keseluruhan konstruk pendekatan belajar dengan pengelompokan sebagai berikut: komponen 1 menjelaskan 24,272\% varian; komponen 2 menjelaskan 8,710\% varian, komponen 3 menjelaskan 7,992\% varian, komponen 4 menjelaskan 6,933\% varian, dan komponen 5 menjelaskan 6,170\% varian. Dengan menggunakan metode varimax rotation with Kaiser Normalization ditemukan ada perbedaan susunan item dalam sub skala sebelum dan sesudah dianalisis dan terbentuk satu sub skala baru, yaitu deep approach-monitoring stuying (DAMS) yang ditunjukkan dalam Tabel 2.

Tabel 2. Analisis faktor ALSI

\begin{tabular}{|c|c|c|c|}
\hline \multirow[b]{2}{*}{ No } & \multirow[b]{2}{*}{ Pernyataan } & \multicolumn{2}{|c|}{ Analisis faktor } \\
\hline & & Sebelum & $\begin{array}{l}\text { Sesudah } \\
\text { (5 factor } \\
\text { loading) }\end{array}$ \\
\hline 1 & Saya mengalami kcsulitan untuk memahami hal yang harus saya ingat & SA & SA \\
\hline 2 & $\begin{array}{l}\text { Saya meninjau kembali hathal yang telah saya kerjakan untuk } \\
\text { mengevaluasi cara berpikir saya }\end{array}$ & MS & MS \\
\hline 3 & Saya berusaha mengerti hal yang saya pelajari & $\mathrm{DA}$ & $\mathrm{DA}$ \\
\hline 4 & Selama ini saya berusaha keras untuk belajar & EM & EMOS \\
\hline 5 & $\begin{array}{l}\text { Apa yang saya pelajari terlihat sebagai potongan-potongan (konten- } \\
\text { konten) vang tidak saling berhubungan }\end{array}$ & SA & SA \\
\hline 6 & $\begin{array}{l}\text { Saya berusaha menghubungkan hasil belajar dengan konteks praktek } \\
\text { atau kehidupan nyata }\end{array}$ & $\mathrm{DA}$ & $\mathrm{DA}$ \\
\hline 7 & Saya cukup sistematik dan terorganisir dalam belajar & OS & EMOS \\
\hline 8 & Saat saya belajar kadang timbul ide yang membuat saya berpikir panjang & DA & DAMS \\
\hline
\end{tabular}


Tabel 2. Analisis faktor ALSI (lanjutan)

\begin{tabular}{|c|c|c|c|}
\hline \multirow[b]{2}{*}{ No } & \multirow[b]{2}{*}{ Pernyataan } & \multicolumn{2}{|c|}{ Arualisis faktor } \\
\hline & & Sebelum & $\begin{array}{l}\text { Sesudah } \\
\text { (5 factor } \\
\text { loading) }\end{array}$ \\
\hline 9 & $\begin{array}{l}\text { Saya melihat bukti empirik (hasil-hasil penelitian) secara cermat untuk } \\
\text { menyimpulkan suatu hal yang sedang saya pelajari }\end{array}$ & DA & DAMS \\
\hline 10 & $\begin{array}{l}\text { Ketika saya mengkomunikasikan ide, saya berpikir sejauh mana saya } \\
\text { menyampaikan pendapat saya }\end{array}$ & MS & DAMS \\
\hline 11 & Saya mengatur waktu belajar saya dengan bijak supaya berguna & OS & EMOS \\
\hline 12 & $\begin{array}{l}\text { Penting bagi saya untuk mengikuti argumen atau melihat alasan dibalik } \\
\text { sesuatu }\end{array}$ & $\mathrm{DA}$ & MS \\
\hline 13 & Saya akan nnenerinla apa yang diajarkanı lanpa nnempertanyakan lagi & $\mathrm{SA}$ & SA \\
\hline 14 & $\begin{array}{l}\text { Saya mencoba mencari cara yang lebih baik untuk menelusuri informasi } \\
\text { mengenai suatu hal yang saya pelajari }\end{array}$ & MS & DAMS \\
\hline 15 & Konsentrasi bukan masalah bagi saya, kecuali saya sangat lelah & EM & EMOS \\
\hline 16 & Jika membaca saya berusaha mengerti apa yang saya baca & DA & DA \\
\hline 17 & Saya belajar tanpa melihat tujuan & $\mathrm{SA}$ & SA \\
\hline 18 & $\begin{array}{l}\text { Jika saya tidak mengerti apa yang saya pelajari, saya akan mencoba } \\
\text { pendekatan belajar yang lain }\end{array}$ & MS & MS \\
\hline
\end{tabular}

$\mathrm{SA}=$ surface approach; $\mathrm{DA}=$ deep approach; $\mathrm{MS}$ = monitoring studying; $\mathrm{OS}$ = organised studying; EM = Effort

Management; EMOS = effort management/organised studying; DAMS= deep approach/monitoring stuying

Dari hasil analisis faktor ALSI dalam penelitian ini ditemukan tiga hal yang cukup menarik, yaitu: 1) semua item dalam sub skala EM dan OS lebih tepat dikelompokkan dalam satu sub skala yang sama, yaitu EMOS dan hal ini sama seperti yang ditemukan Mattick et al. ${ }^{14} ; 2$ ) ditemukan satu sub skala baru yang terbentuk, yaitu sub skala DAMS yang tidak ditemukan Mattick et al. ${ }^{14}$; dan, 3) lima sub skala dalam ALSI terbukti mengukur satu konstruk yang sama, yaitu pendekatan belajar. Hasil analisis korelasi dalam penelitian ini memperlihatkan hubungan yang kuat antara sub skala DA dan MS. Berdasarkan hal ini, sub skala DA dan MS lebih tepat dikelompokan dalam satu sub skala yang sama. Namun, diharapkan penelitian psikometrik untuk validasi ALSI dapat dilakukan di berbagai konteks penelitian dan di negara yang berbeda untuk memperkuat hasil penelitian ini.

Nilai Crönbach alpha tiap sub skala diperlihatkan dalam Tabel 3. Berdasarkan hasil analisis faktor, jika sub skala EM dan OS digabung dalam satu sub skala EMOS dan sub skala DA dan MS juga digabung dalam satu sub skala DAMS diperoleh kenaikan pada nilai Crönbach alpha.

Tabel 3. Nilai rerata dan Crönbach alpha tiap sub skala ALSI

\begin{tabular}{ccccc} 
Subskala & $\begin{array}{c}\text { Nilai } \\
\text { rerata }\end{array}$ & SD & $\begin{array}{c}\text { Crönbach } \\
\text { alpha }\end{array}$ & $\begin{array}{c}\text { Crönbach } \\
\text { alpha }\end{array}$ \\
\hline SA & 2,66 & 0.56 & 0.565 & 0.565 \\
MS & 3,83 & 0.38 & 0.467 & $0.733^{*}$ \\
DA & 4,01 & 0.35 & 0.635 & \\
EM & 3,77 & 0.66 & 0.295 & $0.673^{*}$ \\
OS & 3,44 & 0.74 & 0.659 & \\
\hline
\end{tabular}

Surface approach (SA); monitoring studying (MS); deep approach

(DA); effort management (EM); dan organized studying (OS)

*Nilai Crönbach alpha jika dua sub skala dikelompokan 
Nilai korelasi antara sub skala juga memperlihatkan hubungan yang lemah, kecuali antara sub skala DA dan MS (lihat Tabel 4). Tabel 5 memperlihatkan nilai korelasi antara item-item pernyataan dalam semua sub skala memiliki nilai korelasi yang lemah $(\mathrm{r}<0.6)$. Berdasarkan hasil tersebut, validitas diskriminan dan validitas konvergen tidak dapat dibuktikan pada instrumen ini.

Seorang mahasiswa kedokteran diharapkan memiliki karakteristik seorang pembelajar dewasa di antaranya belajar karena termotivasi secara intrinsik (belajar bukan hanya untuk memperoleh nilai tinggi, tetapi karena tertarik pada sesuatu yang dipelajari) dan menggunakan pendekatan belajar mendalam. ${ }^{15,16,17}$ Dari 160 mahasiswa, sebagian besar menggunakan pendekatan belajar mendalam. Hal ini juga terlihat dari nilai rerata sub skala DA lebih tinggi dibandingkan sub skala yang lain. Hal ini membuktikan bahwa lebih banyak mahasiswa yang memiliki ketertarikan pada hal-hal yang diukur dalam sub skala DA. Hasil ini berbeda dengan yang dilaporkan oleh Jurgens et al. ${ }^{18}$ bahwa lebih banyak mahasiswa program internasional FK UGM yang menggunakan pendekatan belajar dangkal. Hal ini mungkin disebabkan karena ada persaingan yang cukup kuat di antara mahasiswa Program Internasional, sehingga menciptakan suasana pembelajaran yang memaksa mereka untuk menggunakan pendekatan belajar dangkal.

Ada beberapa kelemahan dalam penelitian ini, yaitu: 1) besar sampel yang kecil; 2) response rate yang rendah; dan 3) penelitian ini hanya dilakukan pada satu blok. Pendekatan belajar bersifat kontekstual, ${ }^{19}$ artinya dapat berubah sesuai dengan situasi yang dihadapi, sehingga pendekatan belajar yang digunakan oleh mahasiswa yang menjadi subjek dalam penelitian ini mungkin berbeda saat mereka belajar di blok yang lain.

Tabel 4. Korelasi antar sub skala dalam instrumen ALSI

\begin{tabular}{lrrrrr} 
& \multicolumn{5}{c}{ Inter-Item Correlation Matrix } \\
\cline { 2 - 6 } & SA & \multicolumn{1}{c}{ MS } & DA & EM & OS \\
\hline SA & 1.000 & & & & \\
MS & -.362 & 1.000 & & & \\
DA & -.328 & .605 & 1.000 & & \\
EM & -.204 & .362 & .331 & 1.000 & \\
OS & -.333 & .473 & .287 & .523 & 1.000 \\
\hline
\end{tabular}

Dicetak tebal $=r>0.6$ (hubungan kuat)

Tabel 5. Nilai korelasi antar item dalam ALSI

\begin{tabular}{|c|c|c|c|c|c|c|c|c|c|c|c|c|c|c|c|c|c|c|}
\hline & \multicolumn{18}{|c|}{ Matrix Korelasi Antar Item } \\
\hline & 1 & 2 & 3 & 4 & 5 & 6 & 7 & 8 & 9 & 10 & 11 & 12 & 13 & 14 & 15 & 16 & 17 & 18 \\
\hline 1 & 1.000 & & & & & & & & & & & & & & & & & \\
\hline 2 & -.030 & 1.000 & & & & & & & & & & & & & & & & \\
\hline 3 & -.130 & .277 & 1.000 & & & & & & & & & & & & & & & \\
\hline 4 & -.019 & .307 & .328 & 1.000 & & & & & & & & & & & & & & \\
\hline 5 & .314 & -.115 & -.257 & -.023 & 1.000 & & & & & & & & & & & & & \\
\hline 6 & -.093 & .250 & .427 & .305 & -.210 & 1.000 & & & & & & & & & & & & \\
\hline 7 & -.260 & .248 & .256 & .330 & -.180 & .139 & 1.000 & & & & & & & & & & & \\
\hline 8 & .019 & .165 & .242 & .204 & -.136 & .259 & .043 & 1.000 & & & & & & & & & & \\
\hline 9 & -.019 & .138 & .187 & .119 & -.110 & 322 & .143 & .320 & 1.000 & & & & & & & & & \\
\hline 10 & -.126 & .130 & .246 & .102 & -.145 & .322 & .184 & .310 & .270 & 1.000 & & & & & & & & \\
\hline 11 & -.197 & .313 & .225 & .497 & -.124 & .260 & .481 & .150 & .041 & .251 & 1.000 & & & & & & & \\
\hline 12 & .009 & .185 & .264 & .219 & -.213 & .203 & .221 & .190 & .062 & .218 & .215 & 1.000 & & & & & & \\
\hline 13 & .231 & -.232 & -.115 & -.041 & .077 & -.198 & -.150 & -.111 & .001 & -.100 & -.147 & -.240 & 1.000 & & & & & \\
\hline 14 & -.180 & .270 & .279 & .237 & -.224 & 335 & 336 & .345 & .252 & .281 & .326 & .288 & -.284 & 1.000 & & & & \\
\hline 15 & -.258 & .113 & .130 & .179 & -.112 & .006 & .295 & .097 & .095 & .088 & .298 & .163 & -.136 & .219 & 1.000 & & & \\
\hline 16 & -100 & .102 & .417 & .242 & -.195 & .354 & .090 & .035 & .145 & .130 & .087 & .251 & -.034 & .223 & .090 & 1.000 & & \\
\hline 17 & .168 & -.179 & -.296 & -.105 & .351 & -.222 & -.263 & -.034 & -.142 & -.177 & -.179 & -.213 & .286 & -.227 & -.079 & -.260 & 1.000 & \\
\hline 18 & -.038 & .204 & .214 & .287 & -.141 & .264 & .210 & .158 & .145 & .068 & .171 & .280 & -.168 & .133 & .095 & .153 & -.037 & 1.000 \\
\hline
\end{tabular}




\section{KESIMPULAN}

ALSI memerlukan perbaikan, terutama item dalam sub skala SA. ALSI lebih baik hanya terbagi dalam tiga sub skala, yaitu sub skala SA, EMOS, dan DAMS. Namun, penelitian psikometrik ALSI perlu dilakukan kembali menggunakan sampel yang cukup besar, sehingga dapat diperoleh hasil analisis faktor yang lebih valid.

\section{KONTRIBUSI}

MAL menyusun penelitian dan semua penulis berkontribusi dalam rancangan penelitian ini. MAL melakukan penelitian dan analisis data dilakukan oleh semua penulis. MAL membuat draft makalah dan semua penulis berkontribusi pada penyempurnaan draft hingga draft akhir makalah ini.

\section{UCAPAN TERIMAKASIH}

MAL mengucapkan terima kasih kepada dr. Widyandana, MHPE, Ph.D dan dr. Tridjoko Hadianto, DTM\&H, M.Kes yang memberikan banyak masukan pada penelitian ini. Peneliti mengucapkan terimakasih juga kepada dr. Surya Akbar dan dr. Ashaeryanto yang telah membantu dalam proses pengumpulan data. Kepada Murti Mandawati, S.Kep yang telah membantu analisis data kualitatif. Kepada Ibu Cindy Abram, S.S yang telah menerjemahkan kembali kuesioner ALSI dalam bahasa Inggris.

\section{PERSETUJUAN ETIKA}

Penelitian ini telah mendapatkan persetujuan dari Komite Etik Kedokteran dan Kesehatan FK UGM.

\section{DAFTAR PUSTAKA}

1. Bengtsson M, Ohlsson B. The nursing and medical students motivation to attain knowledge. Nurse Education Today; 2010; 30: 150-6.

2. Zhang LF. University students' learning approaches in three cultures: an investigation of Biggs's 3P model. Journal of Psychology Interdisciplinary and Applied. 2000; 134(1): 37-55.

3. Pimparyon P, Roff S, McAleer S, Poonchai B, Pemba S. Educational environment, student approaches to learning and academic achievement in a Thai nursing school. Medical Teacher. 2000; 22(4): 359-64.
4. Sobral DT. What kind of motivation drives medical students' learning quests? Medical Education. 2004; 38: 950-57.

5. Nijhuis J, Segers M, Gijselaers W. The extent of variability in learning strategies and students' perceptions of the learning environment. Learning and Instruction. 2008; 18: 121-34.

6. Entwistle NJ, Hanley M, Hounsell D. Identifying distinctive approaches to studying. Higher Education. 1979; 8: 365-80.

7. Biggs JB. Student approach to learning and studying: research monograph. Australia: Australian Council for Education Research; 1987.

8. Tait H, Entwistle NJ. Identifying students at risk through ineffective study strategies. Higher Education. 1996; 31: 97-116.

9. Entwistle NJ, Tait H, Mccune V. Patterns of response to an approaches to studying inventory across contrasting groups and contexts. European Journal Of The Psychology Of Education. 2000; 15: 33-48.

10. Entwistle N, McCune V, Hounsell J. Approaches to studying and perceptions of university teaching-learning environments: concepts, measures, and preliminary findings. Edinburgh: Occasional Report 1; 2002.

11. Waty W. hubungan pendekatan pembelajaran mahasiswa dengan ketrampilan klinik dasar dengan nilai Objective Structure Clinical Examination (OSCE) [tesis]. Jakarta (Indonesia): Universitas Indonesia; 2010.

12. Cohen L, Manion L, Morrison K. Research methods in education. New York: Routledge; 2011.

13. Fraenkel JR, Wallen NE, Hyun HH. How to design and evaluate research in education. New York: Mc-Graw Hill; 2012.

14. Mattick K, Dennis I, Bligh J. Approaches to learning and studying in medical students: validation of a revised inventory and its relation to student characteristics and performance. Medical Education. 2004; 38: 535-43.

15. Beckwith JB. Approaches to learning, their context and relationship to assessment performance. Higher Education. 1991; 22(1): 17-30.

16. Trigwell K, Prosser M. Improving the quality of student learning: the influence of learning context and student approaches to learning on learning. Higher Education. 1991; 22(3): 251-66.

17. Diseth G, Martinsen Y. Approaches to learning, cognitive style, and motives as predictors of academic achievement. Educational Psychology. 2003; 23(2): 195207 
18. Jurgens S, Emilia O, Widyandana Relationship between learning approach and motivation to learn among medical students at Universitas Gadjah Mada. Jurnal Pendidikan Kedokteran dan Profesi Kesehatan Indonesia. 2009; 4(1): 26-31.
19. Entwistle NJ. Approaches to learning and perceptions of the learning environment introduction to the special issue. Higher Education. 1991; 22: 201-4. 